\title{
ENSINO DE HISTÓRIA NA BASE NACIONAL COMUM CURRICULAR (BNCC): SENTIDOS DE DIVERSIDADE NOS ANOS INICIAIS
}

\author{
ENSEÑANZA DE HISTORIA EN LA BASE CURRICULAR COMÚN NACIONAL \\ (BNCC): SENTIDOS DE DIVERSIDAD EN LOS AÑOS INICIALES
}

\author{
HISTORY TEACHING IN THE NATIONAL COMMMON CURRICULAR BASE \\ (BNCC): SENSES OF DIVERSITY IN THE EARLY YEARS
}

\author{
Maria Aparecida Lima dos SANTOS ${ }^{1}$ \\ Suzana Lopes Salgado RIBEIRO ${ }^{2}$ \\ Wanessa Odorico ONÓRIO ${ }^{3}$
}

RESUMO: Objetivando compreender os sentidos que a Base Nacional Comum Curricular (BNCC) tenta fixar para o significante diversidade no componente curricular de História, apresentamos neste artigo uma análise que considera o documento como mecanismo discursivo que opera dentro de um regime de verdade a serviço da busca de hegemonia no campo educacional e social. O estudo, de viés qualitativo e de caráter documental e bibliográfico, abordou alguns dos principais fundamentos das concepções que consubstanciam a BNCC. As considerações apontam que a hibridização do significante diversidade oculta sentidos vinculados a um projeto fundamentado na perspectiva da interculturalidade funcional, que preconiza a despolitização do processo educativo pela subordinação do conhecimento em si (os conteúdos de História e a temática da diversidade) ao conhecimento para se fazer algo (discurso das competências).

PALAVRAS-CHAVE: Política de currículo. Ensino de história. Diversidade. Discurso das competências.

RESUMEN: El artículo tiene como objetivo comprender los significados que la Base Curricular Común Nacional (BNCC) intenta corregir el significante diversidad en el componente del plan de estudios de Historia. El texto analiza el documento como un mecanismo discursivo que opera dentro de un régimen de verdad al servicio de la búsqueda de la hegemonía en el campo educativo y social. El estudio cualitativo, de carácter documental y bibliográfico, abordó algunos de los fundamentos principales de las concepciones que encarnan el BNCC. Las consideraciones indican que la hibridación de el significante diversidad oculta significados vinculados a un proyecto basado en la perspectiva de la

\footnotetext{
${ }^{1}$ Universidade Federal de Mato Grosso do Sul (UFMS), Campo Grande - MS - Brasil. Professora Associada da Faculdade de Educação (FAED/UFMS) e Docente no Programa de Pós-Graduação Mestrado Profissional em Ensino de História (UEMS). Doutorado em Educação (USP). ORCID: https://orcid.org/0000-0001-8106-4978. Email:maria.lima-santos@ufms.br

${ }^{2}$ Universidade Federal de Mato Grosso do Sul (UFMS), Campo Grande - MS - Brasil. Professora Visitante no Programa de Pós-Graduação em Educação. Doutorado em História Social (USP). ORCID: http://orcid.org/00000002-0310-0694. E-mail: suzana.ribeiro@ufms.br

${ }^{3}$ Secretaria Municipal de Educação (SEMED), Campo Grande - MS - Brasil. Professora de Educação Física e dos anos iniciais do Ensino Fundamental. Especialização em Relações Étnico-Raciais (UFMS). ORCID: https://orcid.org/0000-0001-7026-2725. E-mail:wanessarico@gmail.com
}

RPGE- Revista on line de Política e Gestão Educacional, Araraquara, v. 24, n. esp. 2, p. 961-978, set. 2020. e-ISSN:1519-9029 
interculturalidad funcional, que aboga por la despolitización del proceso educativo a través de la subordinación del conocimiento mismo (los contenidos de la Historia y el tema de la diversidad) al conocimiento para hacer algo (discurso de compentecias).

PALABRAS CLAVE: Politica curricular. Enseñanza de historia. Diversidad. Discurso de compentecias.

ABSTRACT: The article aims to understand the meanings that the Brazilian document National Common Curricular Base (BNCC) tries to fix for the significant diversity in the curricular component of History. The text analyzes the document as a discursive mechanism that operates within a regime of truth at the service of the search for hegemony in the educational and social fields. The qualitative study, of documentary and bibliographic character, approached the fundamentals of the concepts that consolidate the BNCC. The considerations point out that the hybridization of significant diversity hides meanings linked to a project based on the perspective of a functional interculturality, which advocates the depoliticization of the educational process through the subordination of knowledge itself (the contents of History and the theme of diversity) to knowledge in order to do something (the discourse of competence).

KEYWORDS: Curriculum policy. History teaching. Diversity. Discourse of competence.

\section{Introdução}

A temática da diversidade tornou-se pauta obrigatória para os sistemas escolares nas últimas décadas. Proveniente de demandas dos movimentos sociais - em particular do Movimento Negro, desde o início do século XX, e, mais recentemente, na década de 1980, do Movimento de Trabalhadores em Educação - a diversidade foi sendo gradualmente incorporada aos currículos tanto a partir de práticas de professores que reconheceram a necessidade de atuar em prol de uma reeducação das relações raciais, quanto em decorrência das imposições previstas pelas leis 10.639/2003 e 11.645/2008, que instituíram a obrigatoriedade do estudo da história e da cultura afrodescendente, africana e indígena.

Apesar disso, a tarefa não tem sido realizada de forma pacífica, uma vez que a realização efetiva das mudanças que essa agenda requer implica no enfrentamento de aspectos centrais do chamado sistema-mundo moderno-ocidental, o qual pressupõe a raça e o racismo como seus elementos estruturantes e constituintes ${ }^{4}$ (QUIJANO, 2005).

${ }^{4} \mathrm{O}$ autor descreve as peculiaridades do chamado sistema-mundo/moderno-ocidental. Suas três características fundamentais são que o trabalho não era mais resultante de um processo histórico de uma comunidade ("mera extensão de antecedentes históricos"), mas algo que visava a produção do lucro a partir da venda no mercado. A segunda característica diz respeito ao fato de que essas formações não coexistiam no mesmo espaço, mas em espaços combinados com o mercado e o capital. Por fim, como consequência dos dois primeiros, "para preencher as novas funções, cada uma delas desenvolveu novos traços e novas configurações histórico-estruturais [...]

RPGE- Revista on line de Política e Gestão Educacional, Araraquara, v. 24, n. esp. 2, p. 961-978, set. 2020. e-ISSN:1519-9029 
Os sentidos que se tenta fixar para o significante diversidade no interior da versão homologada em dezembro de 2017 da Base Nacional Comum Curricular (BNCC), ao nosso ver, trazem à tona diferentes dimensões da colonialidade do poder ${ }^{5}$ (QUIJANO, 2005), elemento que envolve diretamente a configuração de sentidos de identidade, de tempo e de espaço intrinsecamente relacionados ao sistema-mundo moderno-ocidental.

A fim de explorar os indícios mencionados, pressupomos ${ }^{6}$ a BNCC, inserida nas reformas curriculares, como mecanismo discursivo que opera dentro de um regime de verdade a serviço da busca de hegemonia no campo educacional e social. Nesse sentido, exacerba-se sua característica de prática cultural e de lugar de enunciação contextualizados em disputas (MACEDO, 2006). Abordados como espaços de poder, os documentos curriculares funcionam como um sistema de significações em que os sentidos são produzidos pelos sujeitos (LOPES; MACEDO, 2011) e, como fruto de políticas públicas que constituem um movimento institucional na busca de viabilizar um discurso oficial sobre educação, projetam identidades pedagógicas e orientam a produção do conhecimento oficial (LOPES, 2002).

Interessa-nos, sob esse ponto de vista, compreender de que forma as relações raciais são posicionadas, identificando os possíveis sentidos que o significante diversidade assume no documento, em geral, e no interior do ensino de História, em particular. Estas pistas podem ajudar a vislumbrar permanências de um sentido de diversidade que se associa a um projeto cuja concepção de interculturalidade é funcional ao sistema capitalista. Além disso, pode fornecer subsídios para refletirmos sobre a perpetuação de lógicas de exclusão que se dão através de currículos estruturados na perspectiva da colonialidade do saber (MALDONADOTORRES, 2007), definida como

um padrão de poder que emergiu como resultado do colonialismo moderno, mas em vez de estar limitado a uma relação formal de poder entre dois povos ou nações, se relaciona à forma como o trabalho, o conhecimento, a autoridade e as relações intersubjetivas se articulam entre si através do mercado capitalista mundial e da ideia de raça. Assim, apesar do colonialismo preceder a colonialidade, a colonialidade sobrevive ao colonialismo. Ela se mantém viva em textos didáticos, nos critérios para o bom trabalho acadêmico, na

estabelecia-se uma nova, original e singular estrutura de relações de produção na experiência histórica do mundo: o capitalismo mundial" (QUIJANO, 2005, p. 229-230).

${ }^{5}$ Para Quijano, quando falamos de colonialidade do poder, referimo-nos aos padrões que foram formulados no decorrer da experiência de colonização, mas que continuaram em vigência mesmo após o fim desse processo econômico, político e social. Um desses padrões é aquele que afirma a ideia de raça como parâmetro para classificar a população mundial. Indica um elemento de colonialidade no padrão de poder hoje hegemônico (QUIJANO, 2005).

${ }^{6} \mathrm{O}$ estudo vincula-se ao projeto de pesquisa "Currículo e ensino de História: sentidos e significados de tempo passado, raça, etnia e diversidade em propostas curriculares (2019/2020)", desenvolvido pela equipe do Grupo de Estudos e Pesquisas sobre Ensino de História e Práticas de Linguagem - Currículo, História e Cultura (GEPEH/UFMS). 
cultura, no sentido comum, na autoimagem dos povos, nas aspirações dos sujeitos e em muitos outros aspectos de nossa experiência moderna. Neste sentido, respiramos a colonialidade na modernidade cotidianamente (MALDONADO-TORRES, 2007, p. 131).

Para apresentar a reflexão, estruturamos o texto em três partes. Na primeira, apontamos alguns dos fundamentos teórico-metodológicos utilizados na investigação realizada, bem como expomos a estrutura da BNCC. Na segunda, introduzimos a análise dos sentidos associados ao significante diversidade, apontando fundamentos do documento, observando elementos de concepções e projetos subjacentes. Por fim, tecemos algumas considerações motivadas pela análise empreendida.

\section{Ensino de História na BNCC}

Em nosso estudo, empenhamo-nos em evoluir de um olhar que concebe a BNCC como um "ente" que "impõe" um "currículo", pronto, prescrito, para outro, que a compreende como produção discursiva que procura fixar significados e sentidos de projetos que buscam hegemonia. Assim,

O currículo é ele mesmo, uma prática discursiva. Isso significa que ele é uma prática de poder, mas também uma prática de significação, de atribuição de sentidos. Ele constrói a realidade, nos governa, constrange nosso comportamento, projeta nossa identidade, tudo isso produzindo sentidos. Trata-se, portanto, de um discurso produzido na interseção entre diferentes discursos sociais e culturais que, ao mesmo tempo, reitera sentidos postos por tais discursos e os recria. Claro que, como essa recriação está envolta em relação de poder, na interseção em que ela se torna possível, nem tudo pode ser dito (LOPES; MACEDO, 2011, p. 41).

Tal perspectiva permite interpelar o componente curricular de História como parte do mecanismo de funcionamento da própria disciplina escolar, constituída em meio aos jogos de interesses que agem tanto no interior das escolas, quanto em outras instâncias da sociedade. Desde seu nascimento, ainda no século XIX, a disciplina escolar de história no Brasil esteve associada a uma função política de conformação da identidade nacional. Dessa forma,

O ensino de história no Brasil apresenta-se, como um terreno de disputas entre diferentes memórias coletivas no qual os sujeitos/alunos são interpelados a se posicionarem e a se identificarem com determinadas demandas de seu presente, tendo como base as relações estabelecidas com um passado inventado como "comum" e legitimado nas aulas dessa disciplina (ANHORN; COSTA, 2011, p. 133). 
Essa disputa, circunscrita em grande parte em torno da noção de identidade insere-se, na atualidade, em permanentes e infindáveis processos de construção e reconstrução, constituindo-se como alvo de disputas das mais diversas ordens (MORAES, 2014) em uma contemporaneidade de "modernidade líquida", em que o "pertencimento" e a "identidade" não têm mais a solidez de uma rocha (BAUMAN, 2005), apresentando-se marcada por conflitos permanentes e por elaborações que a tornam construção sócio-histórico e culturalmente determinada.

Como espaço de constituição de identidades historicamente instituído, a História escolar também tem sido interpelada pelo conteúdo das leis 10.639/2004 e 11.645/2008, mencionadas anteriormente, inserindo-a em uma agenda política na qual os sentidos do passado são buscados em função de uma demanda do tempo presente, apontando para a necessária inclusão de negros e indígenas e configurando o direito à História a esses grupos secularmente excluídos das narrativas históricas veiculadas tanto na escola, quanto fora dela.

A partir dessa perspectiva é que procuramos estruturar um estudo que buscou mapear alguns dos sentidos de diversidade movidos no interior da proposta da BNCC para o componente curricular de História.

Utilizamo-nos, na produção dos dados e na análise, da abordagem qualitativa (GHEDIN; FRANCO, 2011), de caráter documental e bibliográfico (SÁ-SILVA; ALMEIDA; GUINDANI, 2009), para realizar um estudo da versão homologada em dezembro de 2017 da Base Nacional Comum Curricular (BNCC) voltada à Educação Infantil e ao Ensino Médio.

O documento está estruturado em apresentação, introdução (itens: os marcos legais que embasam a BNCC; os fundamentos pedagógicos da BNCC; o pacto interfederativo e a implementação da BNCC), estrutura da BNCC, etapa da Educação Infantil (itens: A Educação Infantil na Base Nacional Comum Curricular; A Educação Infantil no contexto da Educação Básica; os campos de experiências; os objetivos de aprendizagem e desenvolvimento para a educação infantil; a transição da educação infantil para o ensino fundamental), etapa do Ensino Fundamental (itens: o Ensino Fundamental no contexto da Educação Básica; áreas). Em seguida, são apresentados os componentes curriculares organizados em áreas obedecendo a sequência: apresentação dos fundamentos e da estrutura da área; quadro com competências gerais da área; componentes de cada área. Para estes últimos, são introduzidos os fundamentos e o rol de competências para cada componente para o Ensino Fundamental, do $1^{\circ}$ ao $9^{\circ}$ ano, seguido do quadro de conteúdos estruturado em unidades temáticas, objetos de conhecimento e habilidades, conforme o exemplo abaixo. 
Quadro 1 - quadro de conteúdos apresentados na BNCC para o componente História segmento de $1^{\circ}$ ao $5^{\circ}$ ano

\begin{tabular}{|c|c|c|c|}
\hline Ano & $\begin{array}{l}\text { Unidade } \\
\text { Temática }\end{array}$ & Objeto de conhecimento & Habilidades \\
\hline \multirow{3}{*}{10} & \multirow{3}{*}{$\begin{array}{l}\text { Mundo } \\
\text { pessoal: meu } \\
\text { lugar no } \\
\text { mundo }\end{array}$} & $\begin{array}{l}\text { As fases da vida e a ideia de } \\
\text { temporalidade } \quad \text { (passado, } \\
\text { presente, futuro) }\end{array}$ & $\begin{array}{l}\text { (EF01HI01) Identificar aspectos do seu } \\
\text { crescimento por meio do registro das lembranças } \\
\text { particulares ou de lembranças dos membros de } \\
\text { sua família e/ou de sua comunidade. }\end{array}$ \\
\hline & & $\begin{array}{l}\text { As diferentes formas de } \\
\text { organização da família e da } \\
\text { comunidade: os vínculos } \\
\text { pessoais e as relações de } \\
\text { amizade }\end{array}$ & $\begin{array}{l}\text { (EF01HI02) Identificar a relação entre as suas } \\
\text { histórias e as histórias de sua família e de sua } \\
\text { comunidade. } \\
\text { (EF01HI03) Descrever e distinguir os seus } \\
\text { papéis e responsabilidades relacionados à } \\
\text { família, à escola e à comunidade. }\end{array}$ \\
\hline & & $\begin{array}{l}\text { A escola e a diversidade do } \\
\text { grupo social envolvido }\end{array}$ & $\begin{array}{l}\text { (EF01HI04) Identificar as diferenças entre os } \\
\text { variados ambientes em que vive (doméstico, } \\
\text { escolar e da comunidade), reconhecendo as } \\
\text { especificidades dos hábitos e das regras que os } \\
\text { regem. }\end{array}$ \\
\hline
\end{tabular}

Fonte: Brasil (2019, p. 406-407) - adaptado pelos autores

Somente o componente de Língua Portuguesa tem seus conteúdos distribuídos em práticas de linguagem, objetos de conhecimento e habilidades (BRASIL, 2019, p. 67).

Inicialmente, realizamos o levantamento do número de vezes que a palavra diversidade aparece em toda a BNCC a fim de constituir uma visão panorâmica em relação à questão. Identificamos que, em 595 páginas, a palavra diversidade aparece no corpo do texto 140 vezes.

$\mathrm{Na}$ introdução do documento (BRASIL, 2019, p. 7-22), ela aparece 11 (onze) vezes, no corpo de três das "Competências Gerais da Educação Básica" (itens 6, 8 e 9) relacionadas ao acolhimento, à compreensão e à valorização da diversidade.

No excerto que trata do segmento de Educação Infantil (BRASIL, 2019, p. 35-56), diversidade aparece outras três vezes. No trecho referente ao Ensino Fundamental (BRASIL, 2019, p. 57-452), o significante está presente em diferentes componentes curriculares, com maior número de recorrências nas áreas de Linguagens (41) e Ciências da Natureza (23).

Neste artigo, apresentaremos a análise voltada ao componente curricular de História, do $1^{\mathrm{o}}$ ao $5^{\circ}$ ano (anos iniciais do Ensino Fundamental), no corpo do qual o significante diversidade foi localizado em oito passagens. Limitamos nossa exposição a esse segmento, por entender que aqui já apareceram indícios que nos permitiram abordar alguns dos principais fundamentos das concepções que consubstanciam a $\mathrm{BNCC}$ e elucidam aspectos dos projetos de natureza política, econômica e cultural dentro dos quais ela foi gestada. 


\section{Relações raciais no ensino de história: sentidos de diversidade}

No tocante ao documento curricular destinado o ensino de História, encontramos uma introdução (BRASIL, 2019, p. 397-405), na qual se apresentam seus pressupostos para o Ensino Fundamental (BRASIL, 2019, p. 397-402); um quadro de competências específicas para este segmento (p. 402); finalizada pela justificativa e fundamentação que articulam as unidades temáticas, os objetos de conhecimento e habilidades previstos para esse componente, cujos conteúdos aparecem, logo em seguida (BRASIL, 2019, p. 406-415) listados em formato de tabela.

Neste trecho do documento, identificamos cinco ocorrências do significante diversidade, inseridos nos trechos apresentados a seguir.

Quadro 2 - Trechos da Introdução Componente Curricular de História (p. 397-405) nos quais foi localizado o significante diversidade [grifos originais em itálico; em negrito - grifos nossos].
Código do
trecho
Trechos selecionados

\begin{tabular}{|l|l|}
\hline $\begin{array}{l}\text { Trecho 1 - } \\
\text { T1-ICCH }\end{array}$ & $\begin{array}{l}\text { Nesse contexto, um dos importantes objetivos de História no Ensino Fundamental é } \\
\text { estimular a autonomia de pensamento e a capacidade de reconhecer que os individuos } \\
\text { agem de acordo com a época e o lugar nos quais vivem, de forma a preservar ou } \\
\text { transformar seus hábitos e condutas. A percepção de que existe uma grande diversidade } \\
\text { de sujeitos e histórias estimula o pensamento crítico, a autonomia e a formação para a } \\
\text { cidadania (p. 400). }\end{array}$ \\
\hline $\begin{array}{l}\text { Trecho 2 - } \\
\text { T2-ICCH }\end{array}$ & $\begin{array}{l}\text { Todas essas considerações de ordem teórica devem considerar a experiência dos alunos e } \\
\text { professores, tendo em vista a realidade social e o universo da comunidade escolar, bem } \\
\text { como seus referenciais históricos, sociais e culturais. Ao promover a diversidade de } \\
\text { análises e proposições, espera-se que os alunos construam as próprias interpretações, de } \\
\text { forma fundamentada e rigorosa. Convém destacar as temáticas voltadas para a diversidade } \\
\text { cultural e para as múltiplas configurações identitárias, destacando-se as abordagens } \\
\text { relacionadas à história dos povos indígenas originários e africanos. Ressalta-se, também, } \\
\text { na formação da sociedade brasileira, a presença de diferentes povos e culturas, suas } \\
\text { contradições sociais e culturais e suas articulações com outros povos e sociedades (p.401). }\end{array}$ \\
\hline $\begin{array}{l}\text { Trecho 3- } \\
\text { T3 - ICCH }\end{array}$ & $\begin{array}{l}\text { Essa análise se amplia no } 5^{\circ} \text { ano, cuja ênfase está em pensar a diversidade dos povos e } \\
\text { culturas e suas formas de organização. A noção de cidadania, com direitos e deveres, e o } \\
\text { reconhecimento da diversidade das sociedades pressupõem uma educação que estimule } \\
\text { o convívio e o respeito entre os povos (p.404). }\end{array}$ \\
\hline
\end{tabular}

Fonte: Brasil (2019) - adaptado pelos autores

No trecho 1 (T1-ICCH), a palavra diversidade [de sujeitos e de histórias] aparece associada ao estímulo da criticidade, autonomia e cidadania. Ela é posicionada aqui como

${ }^{7}$ A sigla T1-ICCH corresponde a "trecho 1 - Introdução do componente curricular de História".

RPGE- Revista on line de Política e Gestão Educacional, Araraquara, v. 24, n. esp. 2, p. 961-978, set. $2020 . \quad$ e-ISSN:1519-9029 
elemento que potencializa o desenvolvimento de aspectos relacionados à cognição (criticidade), à dimensão psicológica (autonomia) e à dimensão política (cidadania). Chamou nossa atenção que, no parágrafo seguinte a essa afirmativa, muito embora não se conceitualizem esses elementos aos quais a diversidade parece potencializar, mobiliza-se o significante autonomia no contexto dos fundamentos epistemológicos da História, estabelecendo uma relação direta de um aspecto a outro, como é possível observar no trecho abaixo.

A busca de autonomia também exige reconhecimento das bases da epistemologia da História, a saber: a natureza compartilhada do sujeito e do objeto de conhecimento, o conceito de tempo histórico em seus diferentes ritmos e durações, a concepção de documento como suporte das relações sociais, as várias linguagens por meio das quais o ser humano se apropria do mundo. Enfim, percepções capazes de responder aos desafios da prática historiadora presente dentro e fora da sala de aula (BRASIL, 2019, p. 400401, [em itálico - grifos originais do documento; em negrito - grifos nossos]).

A generalização operada na abordagem do significante diversidade, abre "brechas" para que se estabeleça relações com os objetivos do ensino de História justamente em torno de um sentido esvaziado de autonomia, característica que é possível observar também nos significantes destacados no texto original e que "definem" as "bases da epistemologia da História”. Não há elementos no texto que permitam configurar de que "bases" se está falando, pois o documento não fornece referências teóricas que fundamentem os significados daquilo que é apresentado. Longe de um sentido negativo de adulteração, queremos ressaltar que esse aspecto configura a hibridação no interior de documentos curriculares, compreendida como "processos socioculturais nos quais estruturas ou práticas discretas, que existiam de forma separada, se combinam para gerar novas estruturas, objetos e práticas" (GARCIA CANCLINI, 2015, p. XIX). A hibridação aqui produzida vincula diversidade à epistemologia da História por uma dimensão psicológica.

Ainda neste processo, em T2-ICCH, o termo diversidade é utilizado como sinônimo de múltiplo ou variado (“diversidade de análises e proposições”), sentido que não se relaciona às questões étnico-raciais, mas sim cognitivas. Relacionado a esse primeiro sentido, em T3$\mathrm{CCCH}$, em relação de subordinação à dimensão cognitiva, as questões étnico-raciais são posicionadas para significar diversidade ("diversidade cultural e para as múltiplas configurações identitárias, destacando-se as abordagens relacionadas à história dos povos indígenas originários e africanos"). Temos aqui uma configuração que identificamos como elemento recorrente na BNCC e exemplar da hibridação operada: a subordinação da epistemologia do conhecimento histórico, um conhecimento em si, àquele conhecimento para 
se fazer algo. Dessa forma, configura-se uma relação na qual o conhecimento em si se refere aos conteúdos, enquanto o conhecimento para fazer algo se relaciona ao que a BNCC define como competências (MUNHOZ; OLEGÁRIO, 2019, p. 38), um dos fundamentos pedagógicos do documento. Aqui, percebemos a clara alusão a um aspecto pragmático, revelador de uma concepção na qual a Educação responde a um sistema cujo conhecimento só tem sentido enquanto valor de troca (se for útil). Essa tem sido a marca das reformas curriculares no Brasil e no exterior, pois:

O debate, insolúvel e ainda entendido por muitos como central no campo do currículo, entre o conhecimento em si e o conhecimento para fazer algo é endereçado no formato de um currículo em camadas. De um lado, utilizam-se as disciplinas/matérias clássicas como fonte de conteúdos, tratados como conhecimento em si. De outro, assume-se que tais disciplinas não dão conta dos desafios contemporâneos e se propõem temas e, principalmente, capacidades transdisciplinares, para cujo atingimento o conhecimento é meio. Esse deslizamento é complementado pela referência a padrões de aprendizagem, demandados pela cultura da testagem em nível internacional (MACEDO, 2016, p. 54).

A cadeia de equivalências que é produzida pela narrativa insere, portanto, as questões da história dos povos indígenas e africanos em posição subordinada a esse conhecimento para fazer algo, desconfigurando a função formativa do ensino de História, porque subordina também a dimensão política da Educação a “capacidades” cognitivas.

No uso do significante, percebemos um processo de esvaziamento pela eliminação dos elementos que poderiam lhe referenciar mais claramente, indicando quem, de fato, está incluído na "diversidade" definida pelas políticas públicas brasileiras (FERREIRA, 2015, p. 305). O documento nos dá pistas de um preenchimento do significante diversidade por significados genéricos que promovem um deslocamento que o afasta sutilmente das referências às demandas e fundamentos que o vinculam à retórica do Movimento Negro, desvinculando, dessa forma, a questão da luta em promoção de direitos e de chances igualitárias (FERREIRA, 2015, p. 307).

Complementarmente, em T3 - ICCH, indicado no quadro 2, o esvaziamento se repete. O documento propõe que no $5^{\circ}$ ano se analise a diversidade dos povos, culturas e formas de organização. Neste mesmo trecho, é feita menção à noção de cidadania e reconhecimento da diversidade das sociedades, associando-a à ideia de convívio e de respeito entre os povos. Percebemos que nesse último trecho diversidade aparece como um sinônimo de incluir/incorporar, sem referência a trabalho com grupos específicos, o que configura uma flutuação de sentidos, a qual "não se desenvolve [...] por qualquer equívoco, mas pelo jogo 
político (de linguagem) caracterizado pelo excesso da significação e, assim, pelo esvaziamento dos significantes garantidores da articulação pretendida" (MATHEUS; LOPES, 2014, p. 344).

Essa flutuação de sentidos pode ser observada também na parte do documento reservada aos conteúdos para a História, em que encontramos o significante diversidade apenas em três passagens, as quais elencamos no quadro a seguir.

Quadro 3 - Trechos nos quais o significante diversidade aparece relacionado aos conteúdos destinados ao componente curricular de História

\begin{tabular}{|c|c|c|c|c|}
\hline $\begin{array}{l}\text { Código } \\
\text { do } \\
\text { trecho }\end{array}$ & Ano & $\begin{array}{l}\text { Unidade } \\
\text { Temática }\end{array}$ & Objeto de conhecimento & Habilidades \\
\hline \multirow{3}{*}{$\begin{array}{l}\text { Trecho } 1 \\
\text { T1- } \\
\mathrm{CCCH}^{8}\end{array}$} & \multirow{3}{*}{$1^{o}$} & \multirow{3}{*}{$\begin{array}{l}\text { Mundo } \\
\text { pessoal: meu } \\
\text { lugar no } \\
\text { mundo }\end{array}$} & $\begin{array}{l}\text { As fases da vida e a ideia de } \\
\text { temporalidade } \\
\text { presente, futuro) }\end{array}$ & $\begin{array}{l}\text { (EF01HI01) Identificar aspectos do } \\
\text { seu crescimento por meio do } \\
\text { registro das lembranças particulares } \\
\text { ou de lembranças dos membros de } \\
\text { sua família e/ou de sua comunidade. }\end{array}$ \\
\hline & & & $\begin{array}{l}\text { As diferentes formas de } \\
\text { organização da família e da } \\
\text { comunidade: os vínculos } \\
\text { pessoais e as relações de } \\
\text { amizade }\end{array}$ & $\begin{array}{l}\text { (EF01HI02) Identificar a relação } \\
\text { entre as suas histórias e as histórias } \\
\text { de sua família e de sua comunidade. } \\
\text { (EF01HI03) Descrever e distinguir } \\
\text { os seus papéis e responsabilidades } \\
\text { relacionados à família, à escola e à } \\
\text { comunidade. }\end{array}$ \\
\hline & & & $\begin{array}{l}\text { A escola e a diversidade do } \\
\text { grupo social envolvido }\end{array}$ & $\begin{array}{l}\text { (EF01HI04) Identificar as } \\
\text { diferenças entre os variados } \\
\text { ambientes em que vive (doméstico, } \\
\text { escolar e da comunidade), } \\
\text { reconhecendo as especificidades dos } \\
\text { hábitos e das regras que os regem. }\end{array}$ \\
\hline \multirow{4}{*}{$\begin{array}{l}\text { Trecho } 2- \\
\text { T2-CCCH }\end{array}$} & \multirow{4}{*}{$5^{\circ}$} & \multirow{4}{*}{$\begin{array}{l}\text { Povos e } \\
\text { culturas: meu } \\
\text { lugar no } \\
\text { mundo e meu } \\
\text { grupo social }\end{array}$} & $\begin{array}{l}\text { O que forma um povo: do } \\
\text { nomadismo aos primeiros povos } \\
\text { sedentarizados }\end{array}$ & $\begin{array}{l}\text { (EF05HI01) Identificar os processos } \\
\text { de formação das culturas e dos } \\
\text { povos, relacionando-os com o } \\
\text { espaço geográfico ocupado. }\end{array}$ \\
\hline & & & $\begin{array}{l}\text { As formas de organização social } \\
\text { e política: a noção de Estado }\end{array}$ & $\begin{array}{l}\text { (EF05HI02) Identificar } \\
\text { mecanismos de organização do } \\
\text { poder político com vistas à } \\
\text { compreensão da ideia de Estado } \\
\text { e/ou de outras formas de ordenação } \\
\text { social. }\end{array}$ \\
\hline & & & $\begin{array}{l}\text { O papel das religiões e da cultura } \\
\text { para a formação dos povos } \\
\text { antigos }\end{array}$ & $\begin{array}{l}\text { (EF05HI03) Analisar o papel das } \\
\text { culturas e das religiões na } \\
\text { composição identitária dos povos } \\
\text { antigos. }\end{array}$ \\
\hline & & & $\begin{array}{l}\text { Cidadania, } \\
\text { cultural e respeito às diferenças } \\
\text { sociais, culturais e históricas (p. } \\
414 \text { ) }\end{array}$ & $\begin{array}{l}\text { (EF05HI04) Associar a noção de } \\
\text { cidadania com os princípios de } \\
\text { respeito à diversidade, à } \\
\text { pluralidade e aos direitos } \\
\text { humanos. } \\
\text { (EF05HI05) Associar o conceito de } \\
\text { cidadania à conquista de direitos dos } \\
\text { povos e das sociedades, } \\
\text { compreendendo-o como conquista } \\
\text { histórica. (p. 415) }\end{array}$ \\
\hline
\end{tabular}

Fonte: Brasil (2019, grifo nosso)

${ }^{8}$ A sigla T1-CCCH corresponde a "trecho 1 - conteúdos do componente curricular de História".

RPGE- Revista on line de Política e Gestão Educacional, Araraquara, v. 24, n. esp. 2, p. 961-978, set. $2020 . \quad$ e-ISSN:1519-9029 
$\mathrm{Na}$ análise dos trechos, é possível notar que múltiplos sentidos "flutuam" em torno do termo diversidade, o qual é posicionado de forma a incluir os sentidos de inclusão, respeito às diferenças, desigualdade econômica e social, mobilidade social e até mesmo variedade e multiplicidade. Esse afastamento aponta para a exclusão dos referentes associados a diferentes sujeitos sociais, tais como aqueles provenientes das pautas do Movimento Negro, ou das demandas formativas do ensino de História. Em última instância, como observado anteriormente, recoloca a função social da escola, reposicionando-a.

Mais uma vez, é pelo antagonismo às pautas apresentadas pelo Movimento Negro que o discurso da diversidade se institui no documento. É pela negatividade da diversidade vinculada a projetos de formação política que a identidade da diversidade se projeta na BNCC em direção a critérios instrumentais, objetivando hegemonizar um projeto de perspectiva pragmática para a Educação pela afirmação do discurso do mercado, do empresariado, da tecnocracia.

Em consonância a esse movimento, a presença, ainda que em pequeno número, do significante diversidade na narrativa do componente curricular de História, dá indícios de que "a colonialidade do poder nos últimos anos esteve em pleno processo de reacomodação dentro dos desígnios globais ligados a projetos de neoliberalização e das necessidades do mercado; eis aí a 'recolonialidade"” (WALSH, 2009, p. 16).

Essa "reacomodação" é parte estruturante da chamada interculturalidade funcional, que, configurada discursivamente, reconhece os conflitos específicos à diversidade, mas mantêm as estruturas das relações de poder, sustentando as desigualdades e estratégias de corte multicultural-neoliberal. É, portanto, tática integracionista, de "controle do conflito étnico e a conservação da estabilidade social, com o fim de impulsionar os imperativos econômicos do modelo neoliberal de acumulação capitalista, agora 'incluindo' os grupos historicamente excluídos" (WALSH, 2009, p. 16).

Um último elemento que gostaríamos de abordar, e que se relaciona a mais um dos fundamentos filosóficos da concepção sobre a qual a BNCC é erigida, diz respeito ao eixo em torno do qual as unidades temáticas foram estruturadas. Para nortear nossa análise, organizamos as unidades no quadro abaixo. 
Quadro 4 - Rol de temáticas para os anos iniciais do Ensino Fundamental na BNCC

Fonte: Brasil (2019, grifo nosso)

\begin{tabular}{|c|l|}
\hline Série & \multicolumn{1}{|c|}{$\begin{array}{c}3^{\text {a }} \text { versão homologada } \\
\text { (Resolução CNE/CP 22.12 .2017) }\end{array}$} \\
\hline $1^{\circ}$ ano & $\begin{array}{l}\text { Unidades temáticas } \\
\text { Mundo pessoal: meu lugar no mundo; Mundo } \\
\text { pessoal; eu, meu grupo social e meu tempo }\end{array}$ \\
\hline $2^{\circ}$ ano & $\begin{array}{l}\text { A comunidade e seus registros; As formas de registrar } \\
\text { as experiências da Comunidade; O trabalho e a } \\
\text { sustentabilidade da Comunidade }\end{array}$ \\
\hline $3^{\circ}$ ano & $\begin{array}{l}\text { As pessoas e os grupos que compõem a cidade e o } \\
\text { município; O lugar em que se vive; A noção de espaço } \\
\text { público e privado }\end{array}$ \\
\hline $4^{\circ}$ ano & $\begin{array}{l}\text { Transformações e permanências nas trajetórias dos } \\
\text { grupos humanos; Circulação de pessoas, produtos e } \\
\text { culturas; As questões históricas relativas às } \\
\text { Migrações }\end{array}$ \\
\hline $5^{\circ}$ ano & $\begin{array}{l}\text { Povos e culturas: meu lugar no mundo e meu grupo } \\
\text { social; Registros da história: linguagens e Culturas }\end{array}$ \\
\hline
\end{tabular}

Identificamos um raciocínio binário, de exclusão e personalista presente em "mundo pessoal: meu lugar no mundo; mundo pessoal; eu, meu grupo social e meu tempo" (grifos nossos). O sentido apresentado relaciona a ideia de posse ao significante lugar ("meu lugar no mundo"), reforçando a centralidade do Eu na constituição da existência. Além disso, "eu, meu mundo" reforça a ideia da identidade como algo inato e fixo, único e imutável em oposição às reflexões contemporâneas sobre a constituição de identidades móveis, fluidas em um mundo em permanente mudança. Neste trecho, exacerba-se, portanto, o papel da escola e, em particular, a função do ensino de História em promover a afirmação deste Eu Universal.

Ao posicionar o eu como elemento central do componente curricular de História, percebemos um sentido que instituiu uma relação de posse do tempo e da coletividade. $\mathrm{Na}$ cadeia de equivalências que o documento vai estruturando, a diversidade aparece restrita à família e a outras crianças com as quais o sujeito tem contato ("papel dos diferentes sujeitos"; "história da escola"). Aqui é possível observar que esta situação pode permitir que se leia a diferença e a existência do outro como elemento incontornável, que, em função do jogo político pode ser antagonizado como "adversário" ou como "inimigo" (GABRIEL, 2013), sem que se destaque a importância das diferenças como elemento de constituição de identidades (SILVA, 2014).

Um outro elemento a ressaltar quando se observa a progressão instituída para as unidades temáticas é a noção de círculos concêntricos. A perspectiva, já presente em livros didáticos de História, Geografia e de Alfabetização há muitas décadas, marcou o currículo de forma preponderante da disciplina nomeada como Estudos Sociais, instaurada no período da 
Ditadura Militar (1964-1985). Essa concepção curricular propõe que se parta do "concreto", sinônimo de proximidade física (e, portanto, mais "compreensível" - consequente proximidade cognitiva) da criança, para o mais “distante”. Esse aspecto é posicionado como elemento central na própria narrativa do documento, como podemos observar a seguir.

\begin{abstract}
"O exercício do 'fazer história', de indagar, é marcado, inicialmente, pela constituição de um sujeito. Em seguida, amplia-se para o conhecimento de um "Outro", às vezes semelhante, muitas vezes diferente. Depois, alargase ainda mais em direção a outros povos, com seus usos e costumes específicos. Por fim, parte-se para o mundo, sempre em movimento e transformação. Em meio a inúmeras combinações dessas variáveis - do Eu, do Outro e do Nós -, inseridas em tempos e espaços específicos, indivíduos produzem saberes que os tornam mais aptos para enfrentar situações marcadas pelo conflito ou pela conciliação" (BRASIL, 2019, p. 397-398, grifo nosso).
\end{abstract}

No sentido que busca fixar, o documento referenda-se em uma tradição da disciplina escolar de História que posiciona o "Eu" e o "Outro", ambos essencializados, em oposição a um caráter coletivo e diverso de constituição dos sujeitos.

Logo, a análise dos eixos que estruturam os conteúdos de História nos ajuda a vislumbrar o entremear de duas lógicas: a primeira relacionada à imposição de um Sujeito Universal (dimensão filosófica), com fortes indícios das polarizações clássicas, concebidas em dualidades: sujeito e objeto, consciência e mundo, corpo e alma, individual e social, identificados não só no trecho destinado ao ensino de História, mas também na apresentação e introdução da BNCC. Tal primazia do $e u$, reforça a noção de existência de um Sujeito Universal, estável e essencialista, com o qual diversidade/identidade não são interdependentes e não estão sendo constantemente deslocadas no/do espaço sociocultural (HALL, 2011; SANTOS, 2005). Essa concepção, calcada no pensamento moderno, indica um olhar em que "o outro é sempre o outro do mesmo, o outro do próprio sujeito e não o outro sujeito a ele irredutível e de dignidade equivalente" (GABRIEL, 2013, p. 289).

A segunda lógica refere-se ao esvaziamento da função educativa (dimensão pedagógica) do ato de ensinar, cuja linguagem das aprendizagens (objetivos de aprendizagem, competências e habilidades), dimensão centrada no conteúdo, deixa de fora o para quê e o por quem (dimensão educativa). Esse deslocamento, oculto no discurso veiculado pela BNCC, apresenta-se transfigurado em lógica natural de um processo sócio historicamente determinado e inevitável. Entretanto, é preciso destacar que

[...] a linguagem da aprendizagem fica aquém da linguagem educacional, justamente porque, como mencionado, o objetivo da educação nunca é que os alunos aprendam, mas que aprendam algo, para fins particulares e que 
aprendem a partir de alguém. A linguagem da aprendizagem é incapaz de capturar essas dimensões, parcialmente porque o aprendizado denota um processo que, por si só, é vazio em relação ao conteúdo e à direção; e em parte porque aprender, pelo menos na língua inglesa, é um termo individualista e individualizante, enquanto a questão educacional - se, por enquanto, queremos expressá-la em termos de aprendizagem - é sempre uma questão de aprender algo de alguém ${ }^{9}$ (BIESTA, 2012, p. 38, tradução nossa).

Os elementos analisados até aqui apontam que os sentidos de diversidade que se tenta fixar através da BNCC se relacionam com um projeto cujas bases filosóficas e pedagógicas apontam justamente para o seu contrário: o não diverso. Pelo império do Eu e do individualismo e pelo expurgo da dimensão coletiva inerente ao ato educativo e à própria constituição da sociedade, instalam-se como naturais sentidos que visam hegemonizar um projeto de formação que desumaniza o processo educativo.

Em acréscimo, consideramos que a tentativa de desassociar o sentido de diversidade da questão do negro, ou de fatores de ordem cultural e política (GOMES, 2006), movimento que identificamos no documento, reforça a existência do racismo como um sistema estruturante/estruturado, com um fluxo de informações (WEDDERBURN, 2011) através do qual ele se espraia beneficiando sujeitos (em âmbito econômico, social e cultural) e instaura hegemonias de determinados grupos. Dessa forma, as questões raciais inserem-se na narrativa veiculadas pela BNCC na busca por fixar sentidos constituídos no seio da modernidade capitalista, em que, historicamente, "raça e divisão do trabalho foram estruturalmente associadas, reforçando-se mutuamente" (QUIJANO, 2005, p. 231).

\section{Considerações finais}

O trabalho objetivou apresentar uma reflexão sobre como a BNCC busca fixar um sentido para o significante diversidade estabelecendo um fluxo que insere as relações raciais em um projeto marcado pela perspectiva da interculturalidade funcional, implicando na promoção de silenciamento, ocultamento e apagamento de pautas históricas de movimentos sociais.

\footnotetext{
${ }^{9}$ Texto original: [...] the language of learning falls short as an educational language, precisely because, as mentioned, the point of education is never that students learn but that they learn something, for particular purposes and that they learn it from someone. The language of learning is unable to capture these dimensions partly because learning denotes a process that, in itself, is empty with regard to content and direction; and partly because learning, at least in the English language, is an individualistic and individualising term whereas the educational questionif, for the moment we want to phrase it in terms of learning - is always a matter of learning something from someone (BIESTA, 2012, p. 38).
} 
A partir da problematização dos sentidos atribuídos ao significante diversidade na apresentação, introdução da BNCC, bem como no trecho reservado ao componente curricular de História, percebemos movimentos de recontextualização que conferem o papel de um híbrido ao significante diversidade visando seu esvaziamento no que tange às dimensões política e formativa do ensino de História e da Educação em geral, em um movimento simultâneo de aproximação aos princípios de formação para o mercado capitalista ao referendar o pragmatismo embutido na concepção de competências.

Esse esvaziamento também indicou um afastamento das demandas apresentadas pelos movimentos sociais, uma vez que o projeto de identidade presente na BNCC reforça uma concepção de Sujeito Universal, marcada pelo antagonismo entre eu e Outro que, ao não destacar lutas e protagonismos na história brasileira, traz indícios de um olhar etnocêntrico e excludente.

A percepção da BNCC como prática discursiva situada em relações de poder, cujos sentidos visam produzir hegemonia, é considerado por nós fundamental para reposicionar as discussões concernentes à diversidade nos documentos curriculares, uma vez que

O que se encontra sedimentado, contudo, nunca o é de uma vez por todas. Por mais sólidas que sejam as estruturas com as quais interpretamos (lemos) a textualidade política, sempre é possível desconstruí-las, apresentar outras possibilidades de leitura. Sempre estaremos no paradoxo de que fazer política implica deslocar as estruturas, é um ato de romper com o que se sabe, tendo em vista, ao mesmo tempo, de que só pensamos com o que sabemos (ou julgamos saber). Construir outros imaginários pedagógicos nos parece depender de deslocamentos do que se encontra sedimentado (LOPES, 2014, p. 17).

Como projeto político, seja do conjunto dos professores, seja dos movimentos sociais, em particular do Movimento Negro, a retomada das demandas que envolvem a temática da diversidade em sua interrelação com as relações raciais torna-se elemento fundamental em um projeto educativo que pretende formar para uma sociedade democrática. Para isso, ao restabelecermos a primazia das dimensões pedagógica e educativa, cada vez mais ocultadas e subordinadas nos documentos curriculares, preconizamos que a formação integral e emancipadora dos sujeitos esteja pautada em uma perspectiva de interculturalidade crítica, a qual "pretende intervenir en y actuar sobre la matriz de la colonialidad, siendo esta intervención y transformación pasos esenciales y necesarios en la construcción misma de la interculturalidad" (WALSH, 2012, p. 66). 


\section{REFERÊNCIAS}

ANHORN, C. T. G.; COSTA, W. Currículo de História, Políticas da Diferença e Hegemonia: diálogos possíveis Políticas da Diferença e Hegemonia: Educação e Realidade, Porto Alegre, v. 36, n. 1, p. 127-146, jan./abr. 2011.

BAUMAN, Z. Identidade: entrevista a Benedetto Vecchi. Rio de Janeiro: Zahar Editores, 2005.

BIESTA, G. J. J. Giving Teaching Back to Education: Responding to the Disappearance of the Teacher. Phenomenology \& Practice, Universidade de Alberta (Canadá), v. 6, n. 2, p. 35-49, 2012.

BRASIL. Ministério da Educação. Base Nacional Comum Curricular (Educação Infantil, Ensino Fundamental e Ensino Médio). Brasília: MEC/SEF, 2019. Disponível em: http://basenacionalcomum.mec.gov.br/. Acesso em: 04 jul. 2020.

FERREIRA, W. B. O conceito de diversidade na BNCC Relações de poder e interesses ocultos. Revista Retratos da Escola, Brasília, v. 9, n. 17, p. 299-319, jul./dez. 2015. Disponível em: http//www.esforce.org.br. Acesso em: 28 jun. 2020.

GABRIEL, C. T. O "Outro" como elemento incontornável na produção do conhecimento histórico. In: MONTEIRO, A. M.; PEREIRA, A. A. (org.). Ensino de história e culturas afro-brasileiras e indígenas. Rio de Janeiro: Pallas, 2013. p. 287-312.

GARCIA-CANCLINI, N. Culturas híbridas: estratégias para entrar e sair da modernidade. São Paulo: EDUSP, 2015.

GHEDIN, E.; FRANCO, M. A. S. Questões de método: na construção de pesquisa em educação. São Paulo: Cortez, 2011.

GOMES, N. L. Diversidade Cultural, currículo e questão racial: desafios para a prática pedagógica. In: ABRAMOWICZ, Anete; BARBOSA, Lucia Maria de Assunção; SILVÉRIO, Valer Roberto. (Org.). Educação como Prática da Diferença. Campinas, SP: Armazém do Ipê - Autores Associados, p. 21- 40, 2006.

HALL, S. A identidade cultural na pós modernidade. Rio de Janeiro, 2011.

MALDONADO-TORRES, N. Sobre la colonialidad del ser: contribuciones al desarrollo de un concepto. In: CASTRO-GÓMEZ, S.; GROSFOGUEL, R. (org.) El giro decolonial. Reflexiones para una diversidad epistémica más allá del capitalismo global. Bogotá: Universidad Javeriana-Instituto Pensar, Universidad Central-IESCO, Siglo del Hombre Editores, 2007. p. 127-167.

LOPES, A. C. Sentidos de qualidade na política de currículo (2003-2012). Educação \& Realidade, Porto Alegre, v. 39, n. 2, p. 337-357, abr./jun. 2014.

LOPES, A. C. Os Parâmetros Curriculares Nacionais para o Ensino Médio e a submissão ao mundo produtivo: o caso do conceito de contextualização. Educação \& Sociedade, 
Campinas, v. 23, n. 80, p. 386-400, set. 2002. Disponível em: http://www.cedes.unicamp.br. Acesso em: 4 jul. 2020.

LOPES, A. C.; MACEDO, E. Teorias de currículo. São Paulo: Cortez, 2011. p. 184-215.

MACEDO, E. Currículo: Políticas, cultura, poder. Currículo sem Fronteiras, Portugal, v. 6, n. 2. p. 98-113, jul./dez. 2006.

MACEDO, E. Base Nacional Curricular comum: a falsa oposição entre conhecimento para fazer e conhecimento em si. Educação em Revista, Belo Horizonte, v. 32, n. 2, p. 45-67, abr./jun. 2016.

MATHEUS, D. S.; LOPES, A. C. Sentidos de qualidade na política de currículo (2003-2012). Educação \& Realidade, Porto Alegre, v. 39, n. 2, p. 337-357, abr./jun. 2014. Disponível em: https://www.scielo.br/pdf/edreal/v39n2/v39n2a02.pdf. Acesso em: 28 jun. 2020.

MORAES, L. M. S.; MORAES, W. S. A Revolta dos Malês nos livros didáticos de História e a lei 10.639/2003: uma análise a partir da "Epistemologia Social Escolar". In: MONTEIRO, A. M. et al. (org.). Ensino de História: entre desafios epistemológicos e apostas políticas. Rio de Janeiro: Mauad X, 2014.

MUNHOZ, A. V.; OLEGÁRIO, F. Base Nacional Comum Curricular: tensionamentos, invenção e transcriação. In: SILVA, F. de C. T.; XAVIER FILHA, C. (org.). Conhecimentos em disputa na Base Nacional Comum Curricular. Campo Grande: Editora Oeste, 2019.

QUIJANO, A. Colonialidade do poder, eurocentrismo e América Latina. In: LANDER, E. (Org). A colonialidade do saber: eurocentrismo e ciências sociais. Perspectivas latinoamericanas. Argentina: Colección Sur Sur, CLACSO, Ciudad Autónoma de Buenos Aires, set. 2005. p. 227-278.

SÁ-SILVA, J. R.; ALMEIDA, C. D.; GUINDANI, J. F. Pesquisa documental: pistas teóricas e metodológicas. Revista Brasileira de História \& Ciências Sociais, Natal, Ano I, n. I, p. 115, jul. 2009.

SANTOS, M. F. Ancestralidade e convivência no processo identitário: a dor do espinho e a arte da paixão entre Karabá e Kiriku. In: Educação anti-racista: caminhos abertos pela Lei Federal n. 10.639/03. Brasília: Ministério da Educação, Secretaria de Educação Continuada, Alfabetização e Diversidade, 2005. p. 205-229.

SILVA, T. T. A produção social da identidade e da diferença. In: SILVA, T. T. (org.).

Identidade diferença: a perspectiva dos Estudos Culturais. Petrópolis: Editora Vozes, 2014. p. 73-102.

WALSH, C. Interculturalidade crítica e pedagogia decolonial: in-surgir, re-existir e re-viver. In: CANDAU, V. M. (org.). Educação Intercultural na América Latina: entre concepções, tensões e propostas. Rio de Janeiro: 7letras, 2009.

WALSH, C. Interculturalidad y (de)colonialidad: perspectivas críticas e políticas. Visão Global, Joaçaba, v. 15, n. 1-2, p. 61-64, jan./dez. 2012. 
WEDDERBURN, C. M. A Humanidade contra si mesma para uma nova interpretação epistemológica do racismo e de seu papel estruturante na história e no mundo contemporâneo. In: FÓRUM INTERNACIONAL AFRO-COLOMBIANO, 2., 2011, Bogotá. Anais [...]. Bogotá, maio 2011.

\section{Como referenciar este artigo}

SANTOS, M. A.; RIBEIRO; S. L. S.; ONÓRIO, W. O. Ensino de História na Base Nacional Comum Curricular (BNCC): sentidos de diversidade nos anos iniciais. Revista on line de Política e Gestão Educacional, Araraquara, v. 24, n. esp. 2, p. 961-978, set. 2020. eISSN:1519-9029. DOI: https://doi.org/10.22633/rpge.v24iesp2.14326

Submetido em: 30/04/2020

Revisões requeridas em: 26/06/2020

Aprovado em: 30/07/2020

Publicado em: 30/09/2020 